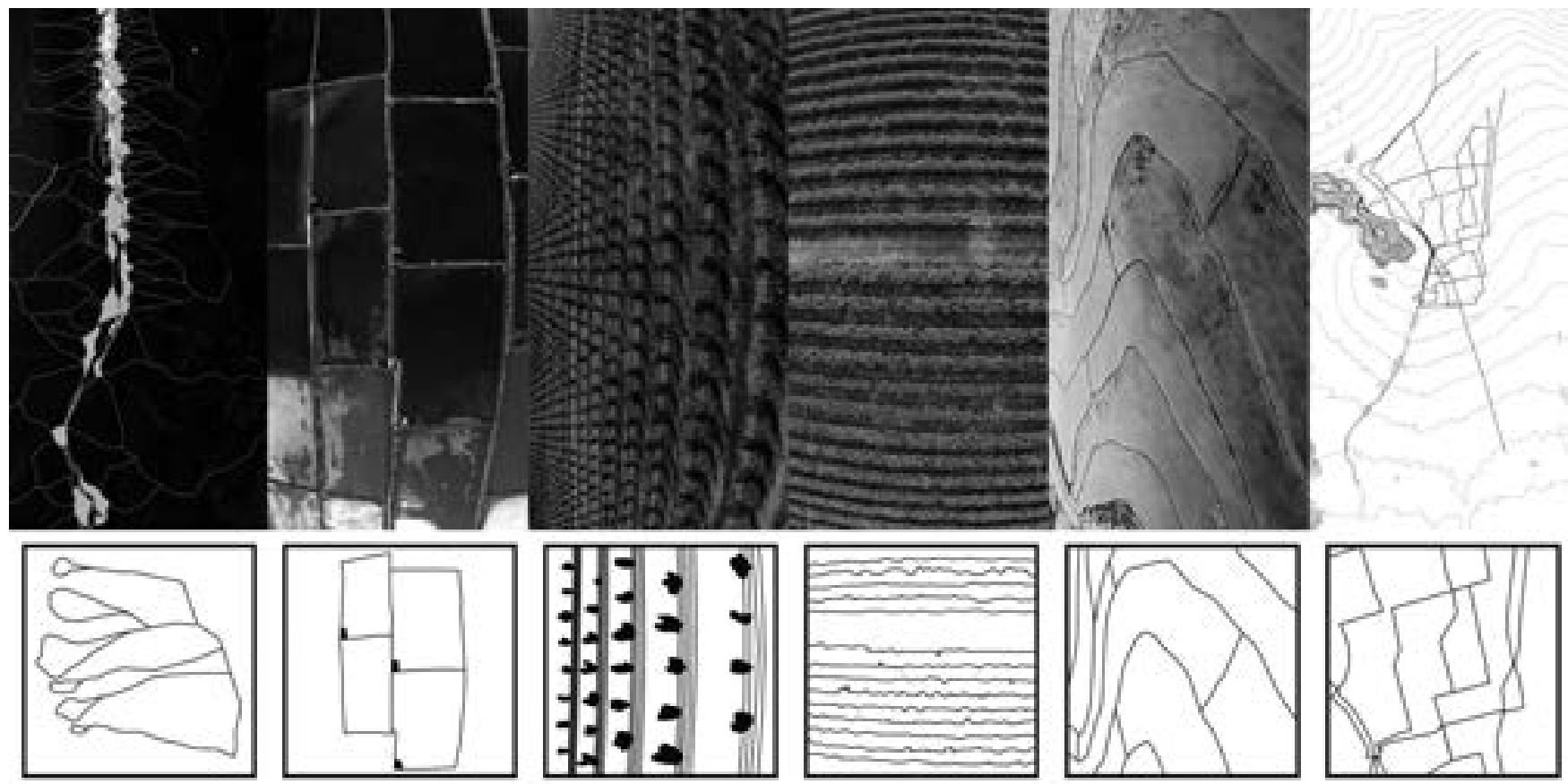

\title{
SOPORTE, DISTANCIA Y ENCUADRE EN LA DEFINICIÓN DEL PAISAJE
}

\section{LOFSCAPES}

Santiago, Chile

¿Cómo representar el paisaje? ¿Cuáles son los instrumentos que permiten capturar su condición efímera? Entendiendo a la cartografía como una herramienta que sirve como un soporte temporal del paisaje, y con la ayuda de drones para registrar esos cambios difíciles de observar por medio del ojo, LOFscapes desarrolla instrumentos de representación que no sólo capturan lo existente sino también permiten especular con posibilidades que sólo aparecen gracias a dichas herramientas.

Palabras clave Representación Cartografía Infografía Dronescapes Herramientas 

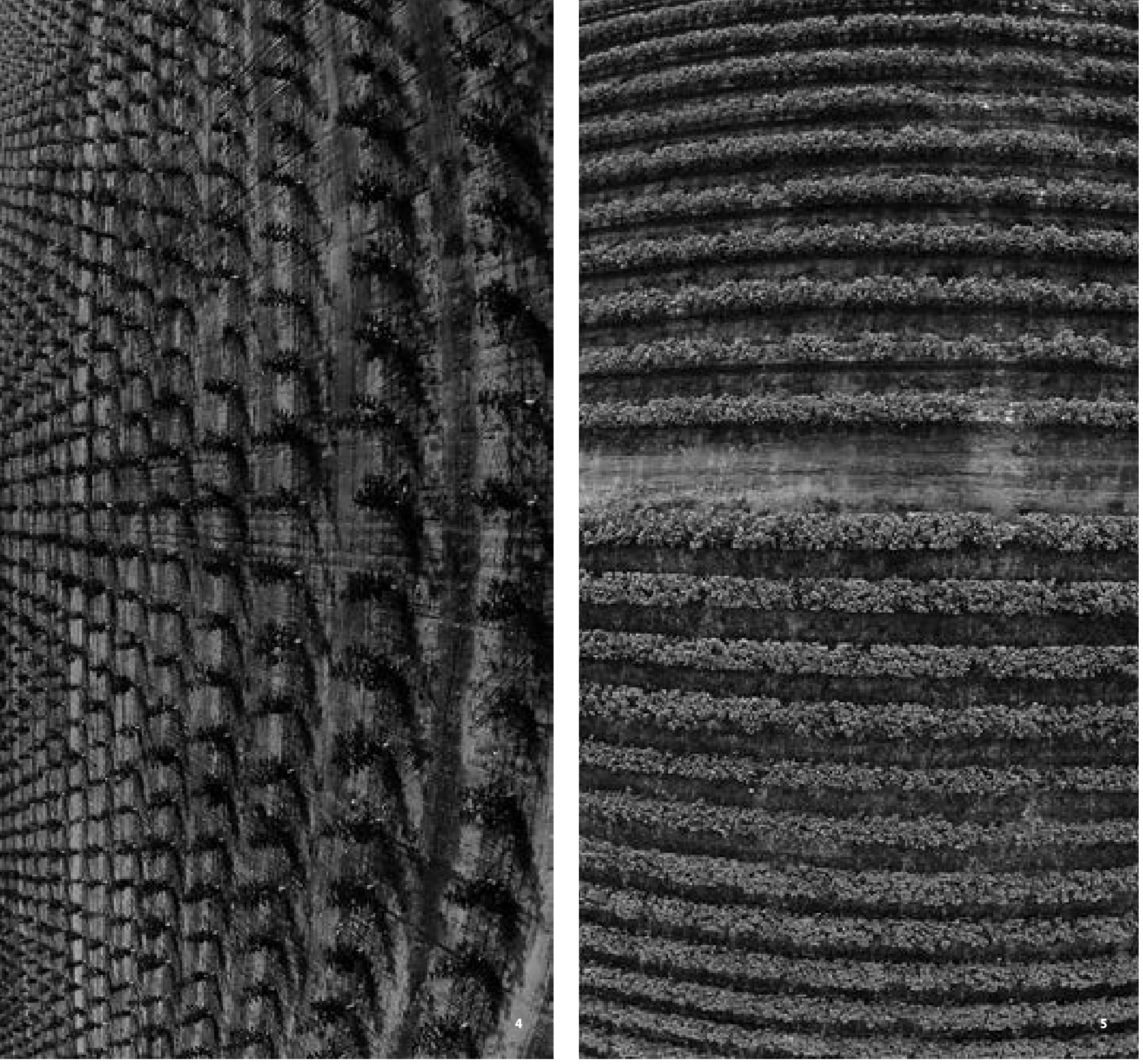

4 Camila Romero. Plantación de Nogales en Parral, Región del Maule, octubre de 2015. / Wallnut plantation in Parral, Maule Region, October 2015 Edición de / edited by: C. Medina \& V. Aguirre. (C) Lofscapes

5 Camila Romero. Plantación de Arándanos en Parral, Región del Maule, octubre de 2015

Cranberry Plantation in Parral, Maule Region, October 2015.

Edición de / edited by:

C. Medina \& V. Aguirre.

(c) Lofscapes materiales a lo largo del tiempo, una de las principales dificultades hoy es, precisamente, la formulación de técnicas de mapeo - o de producción de imágenes capaces de dar cuenta de las complejidades de paisajes siempre en proceso.

Consecuentemente, la identificación de un orden como resultado de un proceso abstrae la condición temporal en una forma racional, reconocible al ojo humano desde una distancia que permite revelar elementos usualmente invisibles. Y, al enmascarar las propiedades de su emplazamiento, especulan sobre nuevas formas de paisaje visibles en las posibilidades de relación que se establecen entre sus partes, una vez que las referencias territoriales han desaparecido. ARQ

\section{Bibliografía / Bibliography}

DIXON HUNT, John. A world of gardens. New York: Routledge, 2012 

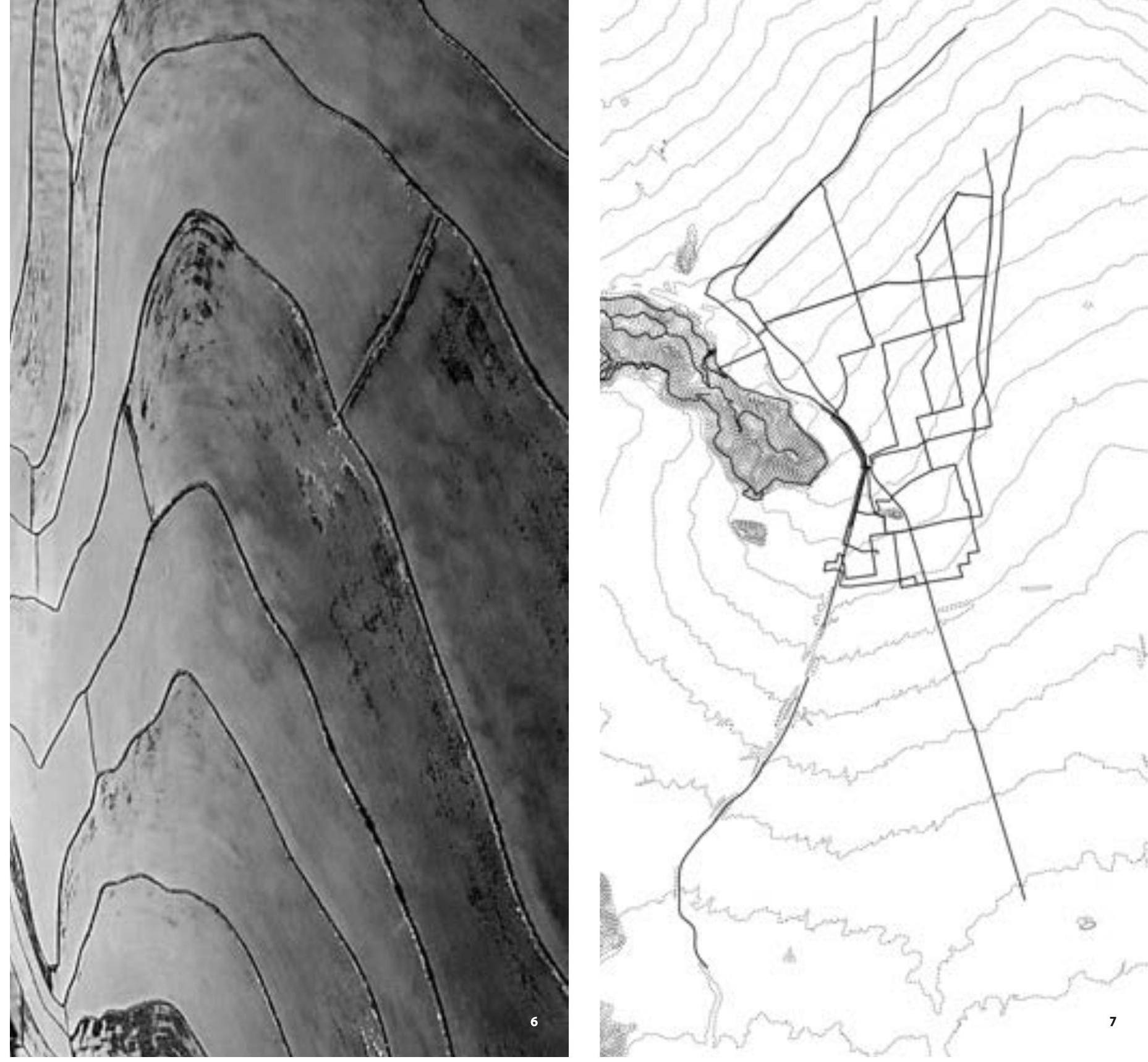

\section{LOFscapes}

$<$ lofscapes@culturadepaisaje.com -www.lofscapes.com>

LOFscapes es un espacio de discusión crítica acerca de la transformación del paisaje chileno. Su objetivo es difundir que el paisaje es el resultado de la articulación entre naturaleza y asentamientos humanos: el paisaje es una ideación, el paisaje se construye, el paisaje se representa, el paisaje se transforma. El colectivo fue formado en marzo del 2015 por Verónica Aguirre, Licenciada en Artes Visuales con mención en grabado y fotografía por la Universidad Finis Terrae (UFT), 2009; Postgrado de Fotografía en Artes Visuales Uf T, 20Io; y Magíster en Arquitectura del Paisaje, Pontificia Universidad Católica de Chile (UC), 20I4; Dominique Bruneau, Arquitecta y Magíster en Arquitectura del Paisaje uc, 20I4; Romy Hecht, Arquitecta y Magíster en Arquitectura Uc, I998; Ph.D en Historia y Teoría de la Arquitectura, Princeton University, 2009; Camila Medina, Arquitecta y Magíster en Arquitectura del Paisaje Uc, 20I4; Camila Romero, Arquitecta y Magíster en Arquitectura del Paisaje uc, 2015; y Francisca Salas, Arquitecta y Magíster en Arquitectura del Paisaje uc, 2014.

6 Camila Romero.

Dronescape, Plantación de Arroz en Longaví, Región del Maule, febrero de 2016. / Dronescape, Rice Planting in Longaví, Maule Region, February 2016. Edición de / edited by: C. Medina \& V. Aguirre (c) Lofscapes

7 Francisca Salas. Ciclorutas LOFscapes 2015-2017, julio de 2017. LOFscapes cycle path 2015-2017, July 2017. Edición de / edited by: C. Medina \& V. Aguirre (C) LOFscapes 